\title{
DIREITO DE ACESSO E USO DA TÉCNICA DE FERTILIZAÇÃO IN VITRO NA PERSPECTIVA DA CORTE INTERAMERICANA DE DIREITOS HUMANOS
}

\section{RIGHT TO ACCESS AND USE THE IN VITRO FERTILIZATION TECHNIQUE: THE PERSPECTIVE OF THE INTER-AMERICAN COURT OF HUMAN RIGHTS}

Leonardo Stoll de Morais

Mestre em Direitos Humanos pelo Centro Universitário Ritter dos Reis - Rede Laureate International Universities. Professor do PPG Lato Sensu em Direito Civil da Universidade Católica de Pelotas. Pesquisador do Laboratório de Pesquisa em Bioética e Ética na Ciência do Hospital de Clínicas de Clínicas de Porto Alegre/UFRGS. E-mail: leonardostollm@gmail.com

Natália Cepeda Fernandes

Mestra em Direitos Humanos pelo Centro Universitário Ritter dos Reis - Rede Laureate International Universities. Advogada. Pesquisadora do Laboratório de Pesquisa em Bioética e Ética na Ciência do Hospital de Clínicas de Clínicas de Porto Alegre.

E-mail: natalia@fernandezfernandes.com.br

\section{Roberta Bristot Silvestrin}

Pós-Doutora pelo Programa de Pós-Graduação em Medicina: Ciências Médicas da UFRGS. Doutora e Mestra em Neurociências pela UFRGS. Biomédica pelo Centro Universitário Feevale. Professora colaboradora do Mestrado profissional em prevenção e assistência a usuários de álcool e outras drogas do Hospital de Clínicas de Clínicas de Porto Alegre. E-mail: betasilvestrin@yahoo.com.br

\section{José Roberto Goldim}

Doutor em Clínica Médica pela Universidade Federal do Rio Grande do Sul (UFRGS) e Mestre em Educação pela UFRGS. Graduado em Ciências Biológicas na UFRGS. Professor colaborador do PPG em Medicina: Ciências Médicas/UFRGS. Chefe do Serviço de Bioética do Hospital de Clínicas de Clínicas de Porto Alegre (HCPA). Coordenador do Laboratório de Pesquisa em Bioética e Ética na Ciência do HCPA/UFRGS. E-mail: jrgoldim@gmail.com

\section{Márcia Santana Fernandes}

Pós-Doutora pelo Programa de Pós-Graduação em Medicina: Ciências Médicas da UFRGS. Doutora em Direito pela UFRGS. Professora do Mestrado Profissional em Pesquisa Clínica do Hospital de Clínicas de Porto Alegre (HCPA) e Professora convidada do Programa de Pós-Graduação em Ciências Médicas da UFRGS. Pesquisadora associada do Laboratório de Pesquisa em Bioética e Ética na Ciência do Centro de Pesquisas do Hospital de Clínicas de Porto Alegre - LAPEBEC/HCPA.

E-mail: marciasantanafernandes@gmail.com

Recebido em: 14/03/2017

Aprovado em: 02/06/2017

Doi: $10.5585 / \mathrm{rdb} . v 17 \mathrm{i} 7.628$ 
RESUMO: Em 28 de novembro de 2012, a Corte Interamericana de Direitos Humanos (CIDH), no caso Artavia Murillo vs. Costa Rica, declarou que os Estados-Partes da Convenção Americana possuem a obrigação de efetivarem políticas públicas que garantam o direito de acesso e uso da técnica de fertilização in vitro à população. A decisão da Corte tem força vinculante para os países signatários da Convenção Americana. Desta forma, o objetivo do presente artigo é avaliar como a CIDH protege o direito de acesso e uso da técnica de fertilização in vitro, especialmente por meio do estudo do caso Artavia Murillo vs. Costa Rica. Para tanto, utilizou-se o método casuístico, sendo a pesquisa qualitativa dividida em duas fases. $\mathrm{Na}$ primeira fase, analisou-se o Sistema Global e Regional Interamericano de Direitos Humanos. Na segunda fase, verificou-se a adequação dos modelos jurídicos brasileiros frente à decisão do caso estudado. A partir da pesquisa realizada foi possível concluir que os modelos jurídicos brasileiros vigentes estão em consonância com a decisão da CIDH, na medida em que asseguram o livre planejamento familiar, por meio do acesso equitativo dos benefícios da tecnologia à população. Em paralelo, percebeuse que existem alguns projetos de leis tramitando no Congresso Nacional que visam instaurar políticas discriminatórias que limitam o acesso e uso da técnica de FIV.

Palavras-chave: Direitos Humanos na América. Fertilização in vitro. Artavia Murillo vs. Costa Rica. Corte Interamericana de Direitos Humanos.

ABSTRACT: On November 28, 2012, the Inter-American Court of Human Rights (IACHR), in the case Artavia Murillo v. Costa Rica, declared that States Parties to the American Convention have the obligation to implement public policies that guarantee the right of access and use of the technique of in vitro fertilization to the population. The decision of the Court has binding force for the signatory countries of the American Convention. In this way, the objective of this article is to evaluate how the IACHR protects the right of access and use of in vitro fertilization technique, especially through the study of the case Artavia Murillo v. Costa Rica. Thus, this is a case-by-case study, with qualitative delineation. The research was divided into two phases. In the first phase, the Global and Regional Inter-American System of Human Rights was analyzed. In the second phase, it was verified the adequacy of Brazilian legal models in relation to the decision of the case studied. Based on the research carried out, it was possible to conclude that the current Brazilian legal models are in line with the IACHR's decision, because the models ensure free family planning through equitable access of the benefits of technology to the population. In parallel, it was noticed that there are some bills of laws being processed in the National Congress that aim to establish discriminatory policies that limit the access and use of the IVF technique.

Keywords: American Human Rights. In vitro fertilization. Artavia Murillo Vs. Costa Rica. InterAmerican Court of Human Rights.

SUMÁRIO: Introdução. 1. O Caso Artavia Murillo vs Costa Rica. 1.1. A proibição da Costa Rica. 1.2. A decisão da Corte Interamericana de Direitos Humanos. 2. A adequação dos modelos jurídicos brasileiros. 2.1. A qualificação jurídica do embrião humano. 2.2. O direito equitativo de acesso e uso da técnica de FIV. 3. Síntese e reflexões. Considerações Finais. Referências. 


\section{INTRODUÇÃO}

O caso Artavia Murillo vs. Costa Rica é paradigmático em matéria de direitos humanos reprodutivos por dois aspectos centrais: primeiro, em razão da Corte Interamericana de Direitos Humanos (CIDH) ter declarado que os Estados-Partes da Convenção Americana têm a obrigação de implementar políticas públicas que efetivem acesso e uso da técnica de FIV; segundo, porque a Corte ao interpretar o artigo 4.1 da Convenção Americana ${ }^{1}$ determinou que o embrião humano criopreservado não é titular do direito humano à vida (CORTE INTERAMERICANA DE DIREITOS HUMANOS, 2012; OEA, 1969).

No contexto do Sistema Regional Interamericano de Direito Humanos ${ }^{2}$, a CIDH possui a função típica e final de interpretar a Convenção Americana (MAZZUOLI, 2004). Isso significa que as suas decisões são diretamente aplicáveis aos países que aderem à norma regional, fato que inclui o Brasil (SHELTON, 2008). Por isso, o entendimento adequado sobre os efeitos da decisão no caso Artavia Murillo vs. Costa Rica é imprescindível.

Alinhando-se a essa necessidade, o propósito do presente artigo é realizar um estudo do caso nominado Artavia Murillo vs. Costa Rica, a fim de sinalizar como a Corte Interamericana de Direitos Humanos compreende o direito de acesso e uso da técnica de fertilização in vitro. Tal objetivo pressupõe, de um lado, o exame dos elementos que compõe o caso, e de outro, a investigação dos modelos jurídicos brasileiros, em face da decisão da CIDH.

Para realizar a pesquisa utilizou-se o método de estudo casuístico, com um delineamento qualitativo. A busca de documentos, envolvendo o caso Artavia Murillo vs Costa Rica, foi dividida em duas fases (internacional e nacional) e foi realizada retrospectivamente no mês de janeiro de 2017.

$\mathrm{O}$ artigo segue organizado em três partes: na primeira parte, apresenta-se o caso Artavia Murillo vs. Costa Rica; na segunda parte, propõe-se uma discussão sobre as implicações da decisão proferida no caso, nos modelos jurídicos brasileiros, em matéria de acesso e uso da técnica de FIV; na terceira parte, define-se uma síntese e uma reflexão a partir dos resultados obtidos.

\section{O CASO ARTAVIA MURILLO VS COSTA RICA}

O estudo do caso Artavia Murillo vs. Costa Rica pressupõe a análise dos fundamentos utilizados pela Corte Suprema de Justiça do Estado da Costa da Rica (Sentença Constitucional $\mathbf{n}^{\circ}$ 2000-02306), que configuraram a proibição de acesso e uso da técnica de FIV no País (Item 1.1), para, em seguimento, serem compreendidas as interpretações proferidas pela Corte Interamericana de Direitos Humanos para invalidar a proibição (Item 1.2).

\footnotetext{
1 “Toda pessoa tem o direito de que se respeite sua vida. Esse direito deve ser protegido pela lei e, em geral, desde o momento da concepção. Ninguém pode ser privado da sua vida arbitrariamente.” In: OEA. Convenção Americana sobre Direitos Humanos, $1969 . \quad$ Disponível em: <http://www.cidh.oas.org/basicos/portugues/c.convencao_americana.htm>. Acesso em: 01/jan/2017.

${ }^{2}$ O Sistema Regional Interamericano de proteção dos direitos humanos tem origem no primeiro semestre de 1948 , quando realizada a $9^{\text {a }}$ Conferência Interamericana entre Estados da região, realizada em Bogotá, Colômbia, em 30 de março a 02 de maio de 1948. Neste evento, foi aprovada a Declaração Americana de Direitos e Deveres do Homem e a Carta da Organização dos Estados Americanos (OEA). Para um estudo geral do Sistema Interamericano, $v$. MAZZUOLI, Valerio de Oliveira, "Tratados internacionais dos Direitos Humanos, (p 956 a 982 ), in Curso de Direito Internacional Público, $5^{\mathrm{a}}$. edição, revista, atualizada e ampliada; Dinah Shelton, Regional protection of human rights, cit., pp. 68-85.
} 


\subsection{A proibição da Costa Rica}

Em 15 de março de 2000, a Sala Constitucional da Corte Suprema de Justiça do Estado da Costa da Rica proferiu a decisão na ação de controle de constitucionalidade do Decreto Executivo n ${ }^{\circ} 24026-S$, que regulava o uso da técnica de fertilização in vitro em todo país.

Em particular, a Sala Constitucional da Corte Suprema de Justiça da Costa Rica ao julgar a constitucionalidade do Decreto Executivo $\mathrm{n}^{\mathbf{0}}$ 24026-S, utilizou dispositivos contidos em normas constitucionais, como a inviolabilidade do direito à vida, e normas regionais, como o artigo 4.1 da Convenção Americana, para declarar que: (a) o ser humano é titular de um direito a não ser privado de sua vida; (b) pessoa natural é aquela concebida, portanto, desde a concepção estamos diante de um ser vivo com direitos assegurados pelo ordenamento jurídico; (c) o direito à vida se declara a favor de todos, sem exceção, devendo o Estado proteger tanto o ser já nascido como o que está por nascer; (d) o embrião humano criopreservado por ter personalidade jurídica merece proteção direta (SALA CONSTITUCIONAL DA CORTE SUPREMA DE JUSTIÇA. COSTA RICA., 2000).

A partir da interpretação do Poder Judiciário da Costa Rica, todos os embriões produzidos in vitro deveriam ser transferidos ao útero materno. Igualmente restou vedada a doação e descarte desse material genético humano. Esse entendimento acarretou uma proibição geral e absoluta do acesso e uso da técnica de FIV no País.

Após a publicação da decisão, o único centro de fertilização da Costa Rica encerrou suas atividades (CROCKIN, SUSAN L.; RIBAS, DELIA; ESCALANTE, GERARDO ; NUSSBAUM, LAUREN; JONES, 2013). Os pacientes diagnosticados com infertilidade, que residiam no país, foram obrigados a constituírem suas famílias em outros estados. Estima-se que pelo menos 140 mil pessoas inférteis ficaram sem acesso à técnica da FIV como meio de concepção (CROCKIN, SUSAN L.; RIBAS, DELIA; ESCALANTE, GERARDO; NUSSBAUM, LAUREN ; JONES, 2013).

A Costa Rica foi o único país no mundo que proibiu o uso e acesso da técnica de FIV, sob pena de sanção criminal. As sanções para quem descumprisse a regra foram equiparadas as penas previstas para o crime de homicídio. A decisão da Sala Constitucional da Costa Rica equiparou o descarte de embriões como um crime de violação à vida humana (SALA CONSTITUCIONAL DA CORTE SUPREMA DE JUSTIÇA. COSTA RICA., 2000).

A Sala Constitucional da Corte Suprema de Justiça da Costa Rica é o maior grau de jurisdição constitucional no país, sendo suas decisões dotadas de força vinculante irreversível (CHIA, EDUARDO A. ; CONTRERAS, 2014). Logo, não caberia recurso da decisão. Portanto, a única forma de reversão seria por meio de uma denúncia perante a Comissão Interamericana de Direitos Humanos.

Em 19 de janeiro de 2001, dez vítimas apresentaram uma petição inicial sob o número 12-361, na Comissão Interamericana de Direitos Humanos. A Comissão aprovou a pertinência e admissibilidade do caso, por meio do Relatório de número 25/04. Em 14 de julho de 2010, a Comissão emitiu várias recomendações ao Estado da Costa Rica, através do Relatório de Mérito 85/10 (COMISSÃO INTERAMERICANA DE DIREITOS HUMANOS, 2010).

A Comissão Interamericana concentrou as suas recomendações nos efeitos causados pela proibição às vítimas. A Comissão declarou que a Costa Rica deveria elaborar uma norma que garantisse o acesso e uso da FIV, bem como deveria erradicar a política institucional discriminatória que foi instaurada na sociedade civil em desfavor das pessoas que possuíam uma infertilidade reprodutiva (COMISSÃO INTERAMERICANA DE DIREITOS HUMANOS, 2010).

No mesmo período da publicação do Relatório de Mérito 85/10, em 2010, foi apresentado um projeto de lei na Assembléia Legislativa da Costa Rica para regulamentar o uso e acesso da técnica da FIV (COSTA RICA., 2010). Entre outros elementos, o projeto de lei 
estabelecia a proteção de todos os direitos da pessoa humana a partir da fecundação e determinava que a técnica de FIV só fosse utilizada "com a condição de que todos os óvulos fertilizados em um ciclo de tratamento fossem transferidos à mesma mulher que os produziu". Igualmente, o projeto de lei previa a proibição "da redução ou destruição de embriões". Além disso, o projeto de lei imputava que "quem, na aplicação da técnica da FIV, destruísse ou reduzisse, ou de qualquer modo matasse um ou mais embriões humanos, seria punido com prisão de um a seis anos" (ASSEMBLÉIA LEGISLATIVA DA COSTA RICA, 2010).

A Organização Panamericana da Saúde (OPS) se pronunciou de forma crítica, contra o projeto lei, ressaltando os riscos de gravidezes múltiplas que podem ocorrer quando todos os óvulos fertilizados em um ciclo de tratamento são transferidos à mesma mulher que os produz, o que, por sua vez, incrementa o risco do aborto espontâneo, complicações obstétricas, nascimentos prematuros e morbidade neonatal (MEIER, BENJAMIN MASON ; AYALA, 2014).

Em particular, o uso da técnica de FIV envolve riscos e benefícios que devem ser ponderados. O sucesso do tratamento inclui múltiplos fatores, dentre eles: o refinamento dos protocolos de estimulação, o risco envolvendo a transferência múltipla de embriões para a receptora e a idade da paciente.

A transferência de múltiplos embriões, em um único ciclo, pode resultar em gestações múltiplas e sérias complicações de saúde para as mães e seus filhos. O parto prematuro e morbidade devido ao baixo peso estão entre as complicações mais comuns dos recém-nascidos. No caso das mães, a gravidez múltipla está correlacionada com maior incidência de préeclâmpsia, infarto do miocárdio, trombose e edema pulmonar (AJDUK; ZERNICKA-GOETZ, 2013).

O reconhecimento dos riscos da gestação múltipla, assim como a melhoria nas técnicas de FIV ao longo do tempo, gerou um forte movimento para a transferência de um número menor de embriões, o que se justifica, também, do ponto de vista do Princípio da Beneficência (BEAUCHAMP; CHILDRESS, 2002).

Alguns países, objetivando reduzir os riscos de nascimento múltiplos, estabeleceram regulamentações ou políticas que limitam o número de embriões que podem ser transferidos por vez, particularmente para mulheres mais jovens, a exemplo da Bélgica que limita o uso de um embrião humano por processo de FIV (E.A. RYBAK, 2009).

De fato, a Costa Rica poderia ter regulado essa questão de uma forma eticamente adequada, salientando a noção educativa e demonstrando que a produção e implantação de um embrião poderia ser uma prática consubstanciada pelo dever prima facie de fazer o bem e evitar riscos previsíveis presentes na transferência múltipla de embriões humanos (BRENA, 2013).

Nesse sentido, a Costa Rica não cumpriu as recomendações da Comissão Interamericana. Por conseqüência, a Comissão apresentou o caso perante a Corte Interamericana de Direitos Humanos. No relatório de apresentação a Comissão esclareceu que a Costa Rica viabilizou políticas institucionais que proibiam absolutamente o uso da técnica de FIV, fato que causou uma ingerência arbitrária nos direitos à vida privada e familiar dos cidadãos. Por isso, a Costa Rica deveria ser responsabilizada internacionalmente pela violação direta dos artigos 1.1, 2, 11.2, 17.2 e 24 da Convenção Americana (CORTE INTERAMERICANA DE DIREITOS HUMANOS, 2012).

\subsection{A decisão da Corte Interamericana de Direitos Humanos}

Em 28 de novembro de 2012, a Corte Interamericana de Direitos Humanos julgou por cinco votos a favor e um contra o caso Artavia Murillo vs Costa Rica, condenando o Estado da Costa Rica a anular a proibição relativa ao acesso da técnica de FIV, por violação dos direitos humanos à vida privada e familiar, à integridade pessoal, à saúde, ao direito de anti- 
discriminação e ao direito de acesso ao desenvolvimento tecnológico (CORTE INTERAMERICANA DE DIREITOS HUMANOS, 2012).

A Corte Interamericana, objetivamente analisou a decisão da Sala Constitucional da Costa Rica, e a partir disso demonstrou que tal decisão promoveu uma supressão desproporcional aos direitos das vítimas.

A decisão da $\mathrm{CIDH}$ ponderou direitos humanos em três momentos: $\left(1^{\circ}\right)$ a Corte avaliou o alcance dos direitos à vida privada e familiar e sua relação com outros direitos convencionais para resolver a controvérsia; $\left(2^{\circ}\right)$ a Corte observou os efeitos da proibição da decisão da Sala Constitucional; $\left(3^{\circ}\right)$ a Corte interpretou o artigo 4.1, a fim de esclarecer que a proteção do direito à vida não impede a realização da técnica de FIV.

A CIDH interpretou o artigo 11 da Convenção Americana, observando que o direito à vida privada constitui um direito humano de conteúdo amplo que garante uma série de fatores associados à vida privada e relacional do indivíduo. A partir dessa interpretação, a Corte considerou que a proibição mantida no Estado da Costa Rica afetava diferentes aspectos da vida privada das vítimas, dentre eles o direito de planejar livremente a concepção familiar (CORTE INTERAMERICANA DE DIREITOS HUMANOS, 2012).

A Corte Interamericana esclareceu que os Estados-Partes da Convenção Americana têm a obrigação de implementar políticas públicas de prestação de serviços à saúde. Ao esclarecer esse ponto, a Corte frisou que direito à saúde não significa, apenas, ausência de doença, mas um estado de completo bem-estar físico, mental e social. Na mesma linha, a Corte definiu o direto à saúde reprodutiva como "o direito dos homens $e$ mulheres de ser informado a ter livre escolha $e$ acesso aos métodos de regulação da fertilidade que são seguros, tecnicamente eficazes, acessiveis e viáveis" (CORTE INTERAMERICANA DE DIREITOS HUMANOS, 2012).

A partir disso, a CIDH entende que o direito humano à saúde reprodutiva deve incluir os benefícios do progresso científico, tais como a técnica de FIV. Logo, a proibição estabelecida pelo Estado da Costa Rica foi caracterizada como uma ingerência arbitrária na vida privada das vítimas, pois as mesmas tiveram que modificar ou alterar a forma de concepção de filhos, fato que causou uma limitação ao acesso das técnicas reprodutivas às pessoas humanas.

Ademais, a CIDH declarou pela primeira vez que o descarte de embriões humanos não viola o direito à vida. Em particular, a Corte, ao interpretar o artigo 4.1 da Convenção Americana, compreende que um embrião humano só terá potencial biológico de ser uma pessoa humana após a implantação no útero e, portanto, o termo concepção, previsto no referido artigo, não poderia ser estendido aos embriões congelados. Como resultado dessa interpretação, a CIDH observou que o uso extensivo dos termos "pessoa" e "ser humano", previstos na Convenção Americana e na Declaração Americana de Direitos e Deveres do Homem, não poderiam implicar no reconhecimento de personalidade jurídica do embrião humano criopreservado, uma vez que o mesmo não é pessoa humana. Além disso, a CIDH ressaltou que o termo "em geral" presente no artigo 4.1 indica que a proteção desde a concepção imposta pela Convenção não é absoluta, e deve ser efetivada com base nos direitos e interesses envolvidos (CORTE INTERAMERICANA DE DIREITOS HUMANOS, 2012).

Por consequência dessas interpretações, a proibição de acesso e uso da técnica de FIV na Costa Rica foi caracterizada como uma violação de direitos humanos, sendo o Estado condenado a anular a vedação estabelecida, bem como reparar monetariamente as vítimas.

\section{ADEQUAÇAO DOS MODELOS JURÍDICOS BRASILEIROS}

A decisão da Corte Interamericana de Direitos Humanos é vinculativa para os 25 Estados-Membros da Organização dos Estados Americanos (OEA), fato que inclui o Brasil e ocasiona a necessidade de avaliação dos modelos jurídicos brasileiros. 
Aproximando-se dessa necessidade, o segundo tópico do presente artigo segue dividido em duas partes: no primeiro item, é explorada a qualificação jurídica do embrião humano nos modelos jurídicos brasileiros; no segundo item, é apresentado o marco regulatório em matéria de acesso e uso da técnica de FIV no Brasil.

\subsection{A QUALIFICAÇÃO JURÍDICA DO EMBRIÃO HUMANO}

No Brasil, o Código Civil Brasileiro (CCB) no artigo $2^{\circ}$ dispõe que "a personalidade civil da pessoa começa com o nascimento da vida, mas a lei põe a salvo, desde a concepção, os direitos do nascituro". Da leitura desse artigo extrai-se que: o marco inicial da existência jurídica da pessoa natural é o nascimento com vida, momento que inicia a capacidade jurídica (BRASIL, 2002).

O nascimento com vida é o fato, natural ou artificial, de separação do feto do útero materno, com a primeira respiração do ciclo vital da pessoa (JUNGES, 1999. p 322). Por essa razão, existem diferentes posições doutrinárias brasileiras sobre a qualificação jurídica do embrião humano, porém se faz necessária uma diferenciação entre embrião intra útero e embrião criopreservado (ALVES, 2012). Isto porque, o embrião humano intra útero pode ser sujeito de direito conforme artigo 1.779 do CCB (BRASIL, 2002), portanto, a problemática brasileira reside na qualificação jurídica do embrião humano criopreservado, igualmente como no caso Artavia Murillo vs Costa Rica.

A legislação brasileira não define de forma específica a qualificação jurídica do embrião humano e como ele deve ser protegido. A Lei de Biossegurança, Lei $n^{0}$. 11.105/ 2005, em seu artigo $5^{\circ}$ permite, para fins de pesquisa e terapia, a utilização de células-tronco embrionárias, produzidas por meio da técnica de FIV (BRASIL, 2005). A Lei estabelece condições para essa utilização, vedando a comercialização de embriões humanos e impondo o consentimento das partes, participantes do processo de reprodução. ${ }^{3}$

$\mathrm{O}$ artigo $5^{\circ}$ da Lei de Biossegurança foi questionado na Ação Direta de Inconstitucionalidade no. 3.510/2008 (SUPREMO TRIBUNAL FEDERAL, 2008). O objeto central dos ministros do STF consistiu em determinar se o embrião humano criopreservado era detentor do direito subjetivo à vida, e, a partir disso, permitir ou não o uso de células-tronco embrionárias em pesquisas cientificas.

O Supremo Tribunal Federal, por maioria, julgou improcedente a ADI, e por consequência confirmou a teoria adotada pelo Código Civil de que somente seres vivos que sobrevivem ao parto são considerados pessoas humanas naturais, dotadas de personalidade civil. Os ministros que votaram pela improcedência, consideraram que a inviolabilidade à vida referida no artigo art. $5^{\circ}$ da Constituição Federal brasileira protege apenas os indivíduos personalizados (BRASIL, 1988).

${ }^{3}$ Brasil. Lei 11.105. 2005. Disponível em http://www.planalto.gov.br/ccivil_03/ ato2004-2006/2005/lei/111105.htm Acessado em 10 jun.2015 Art. 5ํ É permitida, para fins de pesquisa e terapia, a utilização de células-tronco embrionárias obtidas de embriões humanos produzidos por fertilização in vitro e não utilizados no respectivo procedimento, atendidas as seguintes condições:

I - sejam embriões inviáveis; ou

II - sejam embriões congelados há 3 (três) anos ou mais, na data da publicação desta Lei, ou que, já congelados na data da publicação desta Lei, depois de completarem 3 (três) anos, contados a partir da data de congelamento.

$\S 1^{\underline{0}}$ Em qualquer caso, é necessário o consentimento dos genitores.

$\S 2^{2}$ Instituições de pesquisa e serviços de saúde que realizem pesquisa ou terapia com células-tronco embrionárias humanas deverão submeter seus projetos à apreciação e aprovação dos respectivos comitês de ética em pesquisa.

Revista de Direito Brasileira | São Paulo, SP | v. 17 | n. 7 | p. 275 - 290 | Mai./Ago. 2017 
O Supremo Tribunal Federal classificou o embrião humano como objeto de direito, e reafirmou a noção de que o uso do material genético humano não configura bem patrimonial, passível de quantificação econômica (SUPREMO TRIBUNAL FEDERAL, 2008).

Portanto, no Brasil, o embrião humano, mesmo que seja objeto de direito, não será considerado propriedade, pois não há patrimonialidade (o material genético não pode ser quantificado economicamente), e não há circulação interpatrimonial de riqueza, sendo o embrião humano, parte do corpo humano e por isso protegido por direitos de natureza existencial e da personalidade, protegidos pelo Direito Privado brasileiro (MORAIS; FERNANDES, 2014).

\subsection{A proteção do Direito de acesso e uso da técnica de FIV}

A fim de cumprir com os deveres positivos impostos pela Constituição da República Federativa do Brasil de $1988^{4}$, o Ministério da Saúde (MS) publicou em 22 de março de 2005 a Portaria $n^{\circ} 426$ instituindo, no âmbito do SUS, a Política Nacional de Atenção Integral em Reprodução Humana Assistida. Tal norma possibilita a realização dos procedimentos envolvendo as técnicas de Reprodução Humana Assistida de forma universal e gratuita no sistema público de saúde, o que abrange o acesso da técnica de FIV aos pacientes que preencham os requisitos técnicos avaliados por um profissional médico (MINISTÉRIO DA SAÚDE, 2012).

A Portaria $n^{\circ} 426$ do Ministério da Saúde é um ato administrativo do poder executivo que instituiu, no âmbito do SUS, a Política Nacional de Atenção Integral em Reprodução Humana Assistida.

A maior parte da população brasileira é atendida pelo Sistema Único de Saúde (SUS). O sistema foi criado em conformidade com as disposições da CRFB/88, para garantir o acesso universal e igualitário para a promoção, proteção e recuperação da saúde de todos os cidadãos de forma justa. O SUS propõe-se a garantir o acesso médico completo e gratuito para toda a população brasileira. Além de oferecer consultas, exames médicos e hospitalizações, o SUS também promove campanhas de imunização, prevenção e vigilância da saúde, e garante o acesso à técnica de FIV.

A regulação ética do procedimento está prevista na Resolução 2121/2015 do Conselho Federal de Medicina. Tal norma é um ato administrativo, de caráter deontológico, que vincula apenas a categoria profissional médica, e como tal cabe somente a essa categoria avaliá-la e estabelecer sua pertinência ou não dentro do contexto de suas práticas (CUNHA; DOMINGOS, 2013).

A Resolução CFM 2121/2015 sugere um rol de quem poderá acessar a técnica de FIV, e impõe limites e critérios éticos para sua utilização. A norma prevê o acesso da técnica para pessoas capazes, heterossexuais e homossexuais. Além disso, a Resolução permite a criopreservação de sêmen, embrião humano, ovócito, impondo, contudo, o limite da utilização de 02 embriões humanos para mulheres de até 35 anos; 03 para mulheres de 36 a 39 anos; 04 para mulheres acima de 40 anos, (CONSELHO FEDERAL DE MEDICINA (BRASIL)., 2015).

Percebe-se, assim, que a Resolução 2121/2015 estabelece limites referentes à transferência de embriões humanos para o útero materno. Contudo, a limitação imposta não ocasiona a invalidação do uso da técnica, como ocorreu na Costa Rica.

\footnotetext{
${ }^{4}$ Em especial, a Portaria MS no 426 efetiva prestações positivas relativas à proteção do planejamento familiar. Isto porque tal direito previsto na $\mathrm{CFRB} / 88$ cria ao Estado um dever negativo e outro positivo. O dever negativo está relacionado à limitação do Estado em interferir arbitrariamente nas questões envolvendo a vida privada e o planejamento familiar; o dever positivo está associado ao dever de fornecer recursos educacionais e científicos, de forma a criar os mecanismos para que o direito seja exercido de forma livre e consciente. São garantidas, desta forma, ambas as condições para exercício da autonomia: o acesso, com a concessão da educação e dos meios tecnológicos; e liberdade, com a proibição de coerção e interferência arbitrária.
} 
Portanto, no que toca a realidade brasileira, o acesso e uso da técnica de FIV para fins reprodutivos está regulamentado eticamente pela Resolução do Conselho Federal de Medicina 2121/2015 e garantido universalmente pela Portaria do Ministério da Saúde 426/GM de 2005. No entanto, as duas normas, geradas no âmbito administrativo, têm alcance normativo limitado no que compete sua vinculação (CONSELHO FEDERAL DE MEDICINA (BRASIL)., 2015; MINISTÉRIO DA SAÚDE, 2005).

\section{SÍNTESE DOS RESULTADOS E REFLEXÕES}

O que se pretende nesse tópico final é sintetizar os dados obtidos por meio da pesquisa de estudo de caso, bem como promover uma reflexão com base no que foi desenvolvido no primeiro e no segundo tópico.

A pesquisa foi dividida em duas fases. Na primeira analisou-se o Sistema Global e Regional de Direitos Humanos; na segunda, buscou-se avaliar se o Sistema Nacional brasileiro está adequado ao Sistema Global-Regional, em matéria de acesso e uso da técnica de FIV.

Na primeira fase da coleta, o objetivo foi localizar documentos internacionais nos sites oficiais: da Organização das Nações Unidas (ONU); da Organização das Nações Unidas para Educação a Ciência e a Cultura (UNESCO); da Organização Mundial da Saúde (OMS); e da Corte Interamericana de Direitos Humanos (CIDH). Nessa fase, foram utilizados os descritores: Artavia Murillo; Fertilization; Human Rights to in vitro fertilization e Inter-American Court of Human Rights.

$\mathrm{Na}$ segunda fase, buscou-se por documentos normativos nacionais nos seguintes sites oficiais brasileiros: Planalto e Câmara dos Deputados, contendo Leis, Decretos, Resoluções, Projetos de Leis; Conselho Federal de Medicina (CFM); e no Ministério da Saúde. Nessa fase, utilizaram-se os descritores: Fertilização in vitro; Reprodução Humana Assistida; e Direitos Reprodutivos.

Para gerar dados consistentes, toda a pesquisa foi realizada na versão disponível do website das organizações internacionais e nacionais, por meio do navegador Google Chrome. Os dados foram avaliados de forma qualitativa, com base no referencial teórico proposto por Bardin (BARDIN, 2011). Essa forma de análise permitiu a taxonomia de categorias e a identificação dos conteúdos a elas relacionados. Os dados obtidos foram utilizados para construir o raciocínio jurídico desenvolvido nesse artigo e seguem sintetizados em duas partes: Sistema GlobalRegional (3.1) e Sistema Nacional (3.2). 


\subsection{Sistema global-regional}

Concluiu-se a pesquisa da primeira fase com uma amostra total de 07 (sete) documentos, sendo 06 (seis) documentos do Sistema Global e 01 (um) do Sistema Regional de Direitos Humanos. Os resultados seguem sintetizados abaixo (Tabela 1).

\begin{tabular}{|c|c|c|c|c|c|c|}
\hline \multicolumn{2}{|c|}{ Escopo } & Organizaçăo & Titulo do Documento & Data & Tipo & Categoriast \\
\hline \multirow{6}{*}{\multicolumn{2}{|c|}{ Internacional }} & ONU & $\begin{array}{l}\text { Tise of scientific and technological divelopment for } \\
\text { the promotion and protoction of human rights and } \\
\text { fundamental frosdoms }\end{array}$ & 1986 & Deretrizes & la \\
\hline & & ONU & $\begin{array}{l}\text { Deciaration on the Use of Sctentiflc and } \\
\text { Technological Progress in the Interest of Peace and } \\
\text { for the Beneft of Mankind }\end{array}$ & 1975 & Diretrizes & ta \\
\hline & & LNESCO & $\begin{array}{l}\text { Declaraçlo Universal do Genoma Humano e dos } \\
\text { Diteitos Humanos }\end{array}$ & 2002 & Diretrizes & $12,2 a, 32,4 a$ \\
\hline & & UNESCO & $\begin{array}{l}\text { Declaraça Universal de Bioética e Direitos } \\
\text { Humanos }\end{array}$ & 2005 & Diretrizes & $12,2 a, 3 a, 4 a$ \\
\hline & & WHO & $\begin{array}{l}\text { Recent aduances in medically assisted conception: } \\
\text { noport of a WHO scientific growp? }\end{array}$ & 1992 & Disetrizes & La, $3 \mathrm{a}, 5 \mathrm{a}$ \\
\hline & & who & $\begin{array}{l}\text { Juprovise the Reporting of Clinical Trials of } \\
\text { Infortility Troatments RMPRINT) modifing the } \\
\text { CONSORT }\end{array}$ & 2013 & Diretrizes & la \\
\hline \multicolumn{2}{|c|}{ Regional } & $\mathrm{CIDH}$ & Antaila Murtllo x Costa Rica processo no. 12361 & 2003 & Sentença & {$[a, 2 a, 3 a, 4 a, 5 a, 6 a$} \\
\hline \multicolumn{7}{|c|}{$\begin{array}{l}\text { Categorias: } \\
\text { (a) } \operatorname{Rec}\end{array}$} \\
\hline 1. & \multicolumn{6}{|c|}{ Os Estados devern remeitar a autonomia das pessoas humanas no processo de tomada de dectsăo. } \\
\hline 2. & \multicolumn{6}{|c|}{ Os Estados deven coibir a pratrimonializaça do corpo bumano; } \\
\hline 3. & \multicolumn{6}{|c|}{ Os Ertudos devem estabelecer normas anti-điscriminaçăo; } \\
\hline 4. & \multicolumn{6}{|c|}{ Os Estados devem permitir o acesso aos beneficios da tecnologia; } \\
\hline 5. & \multicolumn{6}{|c|}{ Os Estados deven garantir o direito à inviolabilidade à vida privada e familiar; } \\
\hline 6. & \multicolumn{6}{|c|}{ Embriôes bumanos năo ș̆o dotados de personalidade juridica. } \\
\hline
\end{tabular}

A partir das categorias encontradas, é possível inferir que existe um objetivo regulatório por parte de organizações internacionais e nacionais em matéria de acesso e uso da técnica de FIV. Esse objetivo, na maioria dos documentos, visa garantir o livre planejamento familiar, por meio do acesso aos benefícios da tecnologia à população.

Observou-se que a decisão da Corte Interamericana está em consonância com as diretrizes do Sistema Global de proteção dos Direitos Humanos, na medida em que todos os documentos originários da ONU, UNESCO e WHO estabelecem limitações à interferência dos Estados no processo de tomada de decisão de pacientes, envolvendo o uso de técnicas reprodutivas (Tabela 1 ).

Cabe ressaltar que os documentos originários do Sistema Global visam garantir o acesso da população aos avanços da ciência. Contudo, o acesso equitativo da população às tecnologias não elimina a ponderação presente nos documentos sobre os limites éticos envolvidos no seu uso. Por exemplo, o conteúdo do direito de uso e manipulação de embriões humanos foi apresentado juridicamente em 1997, pela Declaração Universal do Genoma Humano e Direitos Humanos. Nesse documento, o artigo $1^{\circ}$, ao apresentar a definição jurídica do genoma humano, afirma uma unidade fundamental baseada em critérios biológicos e axiológicos: "o genoma humano subjaz à unidade fundamental de todos os membros da família humana e também ao reconhecimento de sua dignidade e diversidade inerentes." (ONU -UNESCO, 1997)

O embrião humano como fonte elementar do genoma foi requalificado juridicamente, e em razão disso passou a ter ampliada a proteção da sua dimensão biológica. Essa proteção é inaugurada no documento da ONU com a finalidade existencial, de modo a evitar a redução do uso e manipulação do embrião humano como um bem disponível dos seres humanos.

A fim de concretizar a visão jurídica de que os materiais genéticos humanos não são bens disponíveis no mercado, o artigo $2^{\circ}$ da Declaração Universal do Genoma Humano e Direitos Humanos qualifica o genoma como objeto de relações jurídicas intersubjetivas, e, em face dessa 
qualificação dogmática, atribui ao mesmo característica de bem da personalidade humana ${ }^{5}$. Desta forma, o genoma humano, e, em sentido stricto sensu, os embriões humanos passaram a ser além de uma categoria biológica também uma categoria jurídica que segue qualificada como bem da personalidade não apropriável e fora do comércio (ONU -UNESCO, 1997).

A inclusão da categoria jurídica ligada à perspectiva existencial da pessoa humana não implica na vedação de acesso e uso da técnica de FIV, mas garante que o embrião humano será utilizado para fins lícitos e éticos, exatamente como esclarecido pela Corte Interamericana de Direitos Humanos (CORTE INTERAMERICANA DE DIREITOS HUMANOS, 2012).

Em especial o estudo do caso Arvatia Murillo vs Costa Rica, comprovou que existem dois discursos argumentativos baseados em referenciais teóricos racionais que visam delimitar a eficácia do direito humano à vida.

Para identificar os argumentos que delimitam o marco inicial do direito humano à vida foi fundamental verificar se o discurso utilizado estava associado a um referencial teórico de caráter religioso-moral, ou se o referencial teórico utilizado era de caráter técnico-científico.

A pesquisa demonstrou que o primeiro discurso, do Estado da Costa Rica, foi elaborado a fim de garantir o direito à vida do embrião humano de forma absoluta, com base em um referencial teórico técnico-científico. Em particular, a Costa Rica classificou o embrião humano, primeiro, em ser vivo; segundo, em ser humano; e terceiro, em pessoa natural - detentora de direitos da personalidade. A justificativa de tal entendimento foi baseada em evidências científicas. O Estado da Costa Rica demonstrou que biologicamente o início da vida humana começa com a concepção, ou seja, com a "fertilização ou fecundação", a qual ocorre quando "as membranas das células do esperma e do óvulo se fundem”. A partir disso, esclareceu que o zigoto e um adulto são equivalentes por serem "organismos humanos completos em diferentes etapas do ciclo humano. Acrescentou que o zigoto "não é simplesmente uma célula humana, mas um novo ser humano", que "abriga todas as instruções necessárias para construir o corpo humano, o qual imediatamente inicia uma complexa sequência de eventos que estabelece as condições moleculares para o contínuo processo de desenvolvimento embrionário” e, por divisões sucessivas e diferenciação, formará cada uma das células presentes no embrião, feto, recém-nascido, criança e adulto. Além disso, afirmou que se deve proteger o mais vulnerável dos seres humanos: o embrião, e reconhecer sua dignidade intrínseca além de sua vinculação com o útero materno. A partir disso, concluiu que o embrião é um ser humano, e em conformidade com os artigos 1.2 e 4.1, da Convenção Interamericana, é pessoa natural e merece a proteção concernente aos direitos de personalidade. (COSTA RICA., 2000)

\footnotetext{
${ }^{5}$ Contribui para a reflexão do tema em questão, a discussão envolvida posteriormente no Caso Oliver Brüstle v.s Greenpeace, de 10 de Março de 2011. Esse Caso, julgado pelo Tribunal de Justiça da União Europeia, trata sobre a interpretação da Diretiva da União Europeia, 98/44, no que concerne a proteção jurídica das invenções biotecnológicas, a obtenção de células progenitoras a partir de células estaminais embrionárias humanas, a patenteabilidade ou não dessas células, a exclusão da utilização de embriões humanos para fins industriais ou comerciais, os conceitos de embrião humano e o respeito do princípio da dignidade humana. Sobre o conceito de embrião humano, manifestou-se o Advogado-geral do Tribunal de Justiça da União Européia, Yves Bot, em seu Parecer no Caso: “O artigo $6{ }^{\circ},{ }^{\circ} .^{\circ}$ 2, alínea c), da Directiva 98/44/CE do Parlamento Europeu e do Conselho, de 6 de Julho de 1998, relativa à proteção jurídica das invenções biotecnológicas, deve ser interpretado do seguinte modo:

O conceito de embrião humano é aplicável desde o estágio da fecundação às células totipotentes iniciais e a todo o processo de desenvolvimento e de constituição do corpo humano daí decorrente. É, designadamente, o caso do blastocisto;

Os óvulos não fecundados, nos quais foi implantado o núcleo de uma célula humana amadurecida ou que foram estimulados a dividir-se e a desenvolver-se por partenogénese, incluem-se também no conceito de embrião humano na medida em que a utilização destas técnicas conduza à obtenção de células totipotentes;

Consideradas individualmente, as células estaminais embrionárias pluripotentes, porque não têm, por si mesmas, a capacidade de se desenvolverem num ser humano, não integram este conceito;" (TRIBUNAL DE JUSTIÇA DA UNIÃO EUROPEIA, 2011) in:
} 
O segundo discurso, da Corte Interamericana, foi consolidado por meio de um referencial teórico racional, com o objetivo de declarar que o embrião humano criopreservado não é pessoa natural. Para tanto, a Corte distinguiu os embriões humanos implantados no útero feminino e os embriões humanos extracorpóreos, classificando-os de forma diferente. Para a Corte, o embrião humano implantado no útero feminino terá a inviolabilidade de sua vida garantida, sendo classificado como um ser vivo detentor de direitos fundamentais; $\mathrm{O}$ embrião humano extracorpóreo não terá a inviolabilidade de sua vida garantida, sendo classificado como um ser vivo, objeto de direitos intersubjetivos. Essa posição foi construída a partir da noção biológica de que há dois momentos complementares e essenciais no desenvolvimento embrionário: a fecundação e a implantação. A Corte observou que somente ao se cumprir o segundo momento - a implantação - se fecha o ciclo que permite entender que existe a concepção, constatando que, embora o ser embrionário tenha fecundado o óvulo e dê lugar a uma célula diferente e com a informação genética suficiente para o possível desenvolvimento de um "ser humano", a verdade é que se o embrião humano não for implantado no útero feminino, suas possibilidades de desenvolvimento são nulas. Logo, observaram que um embrião humano extracorpóreo não poderá se desenvolver, já que não receberia os nutrientes necessários, nem estaria em um ambiente adequado para seu desenvolvimento (CORTE INTERAMERICANA DE DIREITOS HUMANOS, 2012).

Considerando isso, a Corte declarou a licitude da conduta do profissional de saúde no processo de FIV, bem como esclareceu que o descarte ou a doação de embriões criopreservados não violam o direito à vida, previsto na Convenção Interamericana (CORTE INTERAMERICANA DE DIREITOS HUMANOS, 2012).

Conquanto tenham os dois discursos finalidades argumentativas opostas, ambos basearam seus argumentos em referenciais teóricos científicos. Portanto, as duas posições se fundamentam em saberes das ciências biológicas, sem, contudo, considerar que há controvérsia sobre o marco inicial da vida humana, inclusive do ponto de vista biológico (DE JESUS, 2014).

A reflexão aqui proposta não busca fazer julgamentos morais das justificativas tomadas. Por isso, acredita-se que a decisão da CIDH merece uma reflexão no que diz respeito à adequação das ações que envolvem a vida e o viver do embrião humano.

Pensando na distinção feita por Agamben com base na diferença existente na língua grega dos significados das palavras associadas à vida: zoe e bios, deve-se ter em mente que Zoe se refere à vida natural, biológica, ao estar vivo, enquanto bios é a vida política, é o bem-viver, é o estar no mundo (AGAMBEN, 1998; GOLDIM, 2006).

Partindo desse pensamento, ao se analisar a justificativa de cada parte sob a noção do viver, vislumbra-se que o embrião humano extracorpóreo ou implantado é parte de um processo consensual de reprodução em que o casal ou indivíduo o concebem com a finalidade de que ele esteja no mundo. Logo, há um desejo mútuo pela vida de relações que será construída. Contudo, esse plano familiar relacionado ao viver do embrião humano poderá ser interrompido em seu curso se o entendimento for de que ele não merece proteção de sua vida, no sentido biológico. $\mathrm{O}$ embrião humano possui vida e é um ser humano em potencial, seja do ponto de vista biológico, metafísico ou ético.

O conceito de AGAMBEN auxilia no entendimento de que o embrião humano em sua individualidade genética e especificidade única, pertence ao mundo, no sentido do viver, no próprio instante da fecundação de um óvulo feminino por um espermatozoide masculino. Desta forma, coincide, a concepção e a personalidade (qualidade de quem é pessoa), pouco importando o processo em que tal concepção ocorra: se artificial ou in vitro, se natural ou em vida. Portanto, acredita-se que o zigoto ou óvulo feminino fecundado como simples embrião de uma pessoa é um ser vivo no seu estado de embrião e não deve ser privado da sua vida nem do seu viver. Por isso, deve-se ter em mente que a produção in vitro e desmesurada de embriões humanos não é justificável do ponto de vista jurídico e ético. Essa posição não invalida o acesso e uso da técnica 
de FIV, mas permite um olhar humanístico sobre a co-responsabilidade dos envolvidos no processo de concepção de um ser vivo.

\subsection{Sistema Nacional Brasileiro}

Em relação ao Sistema Nacional brasileiro, concluiu-se a pesquisa da segunda fase com uma amostra total de 13 documentos. Os resultados seguem sintetizados abaixo (Tabela 2).

\begin{tabular}{|c|c|c|c|c|c|}
\hline Escopo & Organizaça & Título do Documento & Data & Tipo & Categorias \\
\hline \multirow[t]{13}{*}{ Nacional } & Congresso Nacional & $\begin{array}{c}\text { Constitinçáso da Republica Federativa do } \\
\text { Brasil }\end{array}$ & 1998 & $\begin{array}{l}\text { Constiturisào } \\
\text { Federal }\end{array}$ & $1 b, 2 b, 3 b, 4 b$ \\
\hline & Congresso Naciosal & Codigo Civil & 2002 & Lei Ordinária & $1 b, 3 b, 5 b$ \\
\hline & $\begin{array}{l}\text { Conselho Federal de } \\
\text { Medicina }\end{array}$ & RES. 2.121/2015 & 2015 & $\begin{array}{l}\text { Resoluça } \\
\text { Normatrva }\end{array}$ & $6 b, 12 b, 13 b$ \\
\hline & Ministèrie da Saùde & Portaria $n^{2} 3.149$ & 2012 & Portaria Federal & $6 \mathrm{~b}, 9 \mathrm{~b}, 13 \mathrm{~b}$ \\
\hline & Congresso Nacional & $P L-115 / 2015$ & 2015 & Projeso de Lel & $3 b, 7 b, 8 b$ \\
\hline & $\begin{array}{l}\text { Supremo Tribumal } \\
\text { Federal }\end{array}$ & ADI 3.5102008 & 2008 & Decisâo judicial & $5 \mathrm{~b}, 6 \mathrm{~b}, 10 \mathrm{~b}, 12 \mathrm{~b}$ \\
\hline & Congresso Nacional & $P L-489 / 2007$ & 2007 & Projeto de Lei & $5 b$ \\
\hline & Congresso Nacional & Lei no $11.105 / 2005$ (Lei de Biossegurança) & 2005 & Lei Ordinària & $10 b, 12 b$ \\
\hline & Congresso Nacional & $\mathrm{PL}-5624 / 2005$ & 2005 & Projeto de Lei & $3 b, 12 b$ \\
\hline & Congresso Naciosal & $\mathrm{PL}-4889 / 2005$ & 2005 & Projeto de Lei & $7 \mathrm{~b}$ \\
\hline & Congresso Nacional & $P L-1135 / 2003$ & 2003 & Projeto de Lei & $7 b$ \\
\hline & Congresso Nacional & $\mathrm{PL}-4665 / 2001$ & 2001 & Projeto de Let & $1 \mathrm{tb}$ \\
\hline & Congresso Nacional & PL $-2855 / 1997$ & 1997 & Projeto de Lei & $3 b, 12 b$ \\
\hline
\end{tabular}

\begin{tabular}{|c|c|}
\hline \multicolumn{2}{|c|}{ Categorias: } \\
\hline (b) & Regulamentaçăo normativa: \\
\hline 1. & Estabelece a inviotabilidade da vida privada (privacidade), \\
\hline 2. & Institui o direito de nio softer discriminaçio; \\
\hline 3. & Determina o direito ao livre planejameato familiar: \\
\hline 4. & Estabeiece o acesso a saide como dever do Estado; \\
\hline 5. & Estabelece o mascimento com vida, como marco inicial dos direitos de personalidade; \\
\hline 6. & Permite o acesso e uso da tecnica de FIV; \\
\hline 7. & Proibe o descarte de embriōes humanos. \\
\hline 8. & Estabelece sançdes criminais en caso de descarte e eliminaçào de embrides humanos; \\
\hline 9. & Institui o acesso universal e gratuito das tecnicas de FIV \\
\hline 10. & Determina que os embrī̄es humanos criopreservados sdo objetos de direito; \\
\hline 11. & Estabelece o acesso e uso da tecrica de FIV, apenas para casais beterossexuais, \\
\hline 12. & Permite a doaçóo e descarte de embriòes humanos excedentirios. \\
\hline 13. & Garante o acesso das técnicas de FIV por pessoas solteiras e por casais LGBT s \\
\hline
\end{tabular}

Os dados indicam que a regulação atual da técnica de FIV no Brasil é fragmentada, escassa e setorial (BRUNO TORQUATO DE OLIVEIRA NAVES, 2015). Assim, para visualizar o modelo jurídico brasileiro que garante o direito de acesso e uso da técnica de FIV foi necessário realizar um processo de conexão de normas encontradas e originárias de diferentes fontes.

O método de Auto-integração ${ }^{6}$ permitiu a conexão sistemática das normas, relacionando textualmente em seu sentido e interpretativamente em seu contexto (BOBBIO, 2007). A possibilidade de conexão, por meio desse método, evidenciou que o arcabouço normativo brasileiro de proteção ao direito de acesso e uso da técnica de FIV está previsto na: Constituição da República Federativa do Brasil <<no direito ao livre planejamento familiar (art. 226, §7, da CRFB/88) e como o direito à saúde (art. 196, da CRFB/88) >>; na qualificação jurídica do embrião humano do Supremo Tribunal Federal (ADI 3.510/2008); nas normas de Direito Privado < marco inicial da pessoa humana e nos direitos da personalidade, de privacidade e de disposição do próprio corpo (arts. $2^{\circ}, 14$ e 21 do CCB); na vedação da comercialização de materiais biológicos (Lei de Biossegurança)>>; nas normas administrativas, como na Diretrizes éticas na área de acesso e uso das técnicas de reprodução humana assistida (Resolução CFM 2121/2015) e na Portaria do Ministério da Saúde 426/GM que prevê o acesso universal e gratuito

\footnotetext{
${ }^{6}$ Auto-integração é método utilizado quando o intérprete recorre ao próprio sistema, no âmbito da fonte dominante. Os elementos que compõem a Auto-integração: Analogia; Princípios gerais de direito e o Mandado de injunção. Sobre os métodos de integração ver: BOBBIO, Norberto. Teoria Geral do Direito. São Paulo: Martins Fontes, 2007, p. 287.
} 
do uso da técnica a todos os cidadãos brasileiros. Todo esse arcabouço normativo indica que a proteção de acesso e uso da FIV, no Brasil, garante direitos humanos à vida privada e familiar, à integridade pessoal, à saúde, ao direito de anti-discriminação e ao direito de acesso ao desenvolvimento tecnológico, portanto, trata-se de um modelo jurídico adequado à decisão da Corte Interamericana de Direitos Humanos.

Logo, no que toca os resultados da segunda fase da pesquisa, identificou-se que a legislação nacional está em consonância com a decisão da CIDH, pois a maioria dos documentos sugere que o Estado brasileiro e os profissionais de saúde devem respeitar o direito à autonomia privada dos pacientes. Em paralelo, percebeu-se que alguns projetos de leis nacionais estão em desacordo com a decisão. Principalmente, porque alguns deles proíbem o descarte de embriões e outros visam limitar o direito de acesso a técnica de FIV. (Tabela 2).

\section{CONCLUSÃO}

A Corte Interamericana de Direitos Humanos protege o direito de acesso e uso da técnica de fertilização in vitro (FIV), com base em três critérios essenciais. Primeiro, compreende que o embrião humano criopreservado não é titular do direito humano à vida, pois não é pessoa natural. Segundo, declara que os Estados não devem interferir arbitrariamente nos direitos reprodutivos de casais e cidadãos. Terceiro, sugere que os Estados devem adotar medidas positivas para efetivarem o direito de acesso aos benefícios do desenvolvimento científico à população.

O estudo de caso realizado ampliou a discussão do Sistema Regional de Direitos Humanos para o campo dos modelos jurídicos brasileiros, sendo possível identificar que, no Brasil, o embrião humano criopreservado não é pessoa natural, mas objeto de direitos intersubjetivos, sendo lícito o descarte e doação de embriões para fins altruísticos. Ademais, a pesquisa evidenciou que o Estado brasileiro possui uma política universal e gratuita, no âmbito do SUS, que garante o direito de acesso e uso da técnica de FIV aos casais heterossexuais e homossexuais, sendo tal técnica regulada eticamente pelo Conselho Federal de Medicina por meio da Resolução 2121/2015.

Apesar de a legislação nacional estar em consonância com o Sistema Global e Regional de Direitos Humanos, verificou-se que há duas posições conflitantes no Brasil: (i) uma atual e vigente que está adequada ao entendimento da CIDH sobre o papel do Estado no acesso equitativo da população ao progresso científico; (ii) e uma inadequada e futura que visa implementar políticas discriminatórios, sobretudo, que objetiva instaurar modelos jurídicos similares ao que vigorou na Costa Rica, por meio da aprovação de Leis Ordinárias que limitam o acesso e uso da técnica de FIV.

\section{REFERÊNCIAS}

AGAMBEN, G. O poder soberano e a vida nua. Lisboa: Presença, 1998.

AJDUK, A.; ZERNICKA-GOETZ, M. Molecular Aspects of Medicine Quality control of embryo development. Molecular Aspects of Medicine, v. 34, n. 5, p. 903-918, 2013.

ALVES, C. A. Aspectos da doação de embriões humanos no cenário brasileiro. Revista Trimestral de Direito Civil-RTDC, v. 49, p. 69-100, 2012.

ASSEMBLÉIA LEGISLATIVA DA COSTA RICA. Projeto de Lei sobre Fecundação In Vitro e Transferência Embrionária, 2010. 
BARDIN, L. Análise de conteúdo. Lisboa. 2011.

BEAUCHAMP, T.; CHILDRESS, J. F. Princípios de ética biomédica. São Paulo: Edições Loyola, 2002.

BOBBIO, N. Teoria Geral do Direito. São Paulo. 2010.

BRASIL. CONSTITUIÇÃO DA REPÚBLICA FEDERATIVA DO BRASIL, 1988.

BRASIL. Código Civil Brasileiro, Lei 10. 406/02, de 10 de janeiro de 2002. Congresso Nacional. BRASIL, 2002. Disponível em: <http://www.planalto.gov.br/CCivil_03/leis/2002/L10406.htm>. Acesso em: 15 jan. 2017

BRASIL. Lei de Biossegurança. Lei 11.105 de 24 de março de 2005. Congresso Nacional. BRASIL, 2005. Disponível em: <http://www.planalto.gov.br/ccivil_03/_ato20042006/2005/lei/111105.htm>. Acesso em: 10 jan. 2017

BRENA, I. Comments to the judgment of the Court of human rights case Artavia Murillo and others (in vitro fertilization) vs. Costa Rica. Boletin Mexicano de Derecho Comparado, n. 137, p. pp.795-803, 2013.

BRUNO TORQUATO DE OLIVEIRA NAVES, M. DE F. F. DE S. Panorama bioético e jurídico da reprodução humana assistida no Brasil. Revista Bioética y Derecho, p. 64-80, 2015.

CHIA, EDUARDO A.; CONTRERAS, P. Análisis de la sentencia Artavia Murillo y otros ("fecundación in vitro") v. Costa Rica de la Corte Interamericana de Derechos Humanos. Estudios constitucionales: Revista del Centro de Estudios Constitucionales, n. 1, p. pp.567-585, 2014.

COMISSÃO INTERAMERICANA DE DIREITOS HUMANOS. Relatório de Mérito $n^{\circ}$ 85/10, Caso 12.361. Costa Rica, 14 de julho de 2010. 2010.

CONSELHO FEDERAL DE MEDICINA (BRASIL). Resolução $n^{o}$ 2.121/2015, 2015. Disponível em: <http://www.portalmedico.org.br/resolucoes/CFM/2015/2121_2015.pdf>. Acesso em: 1 jan. 2017.

CORTE INTERAMERICANA DE DIREITOS HUMANOS. Artavia Murillo vs Costa Rica, 2012. Disponível em: <http://www.corteidh.or.cr/F5C1570B-CA0A-41A8-809BCB48DB858AAA/FinalDownload/DownloadId8C457830B80A56462FBEBC78B3672ED3/F5C1570B-CA0A-41A8-809BCB48DB858AAA/docs/casos/articulos/seriec_257_por.pdf>. Acesso em: 1 jan. 2017

COSTA RICA. Projeto de Lei sobre Fecundação In Vitro e Transferência Embrionária, Expediente 17.900. Costa Rica. 22 de outubro de 2010. 2010.

CROCKIN, SUSAN L.; RIBAS, DELIA; ESCALANTE, GERARDO; NUSSBAUM, LAUREN; JONES, H. W. Costa Rica's absolute ban on in vitro fertilization deemed a human rights violation: implications for U.S. assisted reproductive technology policy and "personhood" initiatives. Fertility and Sterility, v. Vol.100(2), p. pp.330-333, 2013. 
CUNHA, L. R. DA; DOMINGOS, T. DE O. Reprodução Humana Assistida: A Resolução 2013/13 do Conselho Federal de Medicina (CFM). Revista de Direito Brasileira, v. 6, n. 3, p. 273-290, 1 dez. 2013.

DE JESUS, L. M. A pro-choice reading of a pro-life treaty: the Inter-American Court on Human Rights' distorted interpretation of the American Convention on Human Rights in Artavia v. Costa Rica. Wisconsin International Law Journal, v. Vol.32(2), p. pp.223-266, 2014.

E.A. RYBAK, H. J. L. Egg freezing, procreative liberty, and ICSI: the double standards confronting elective self-donation of oocytes. Fertil Steril, v. 92, p. 1509-1512, 2009.

JUNGES, J. R. BIOÉTICA: PERSPECTIVAS E DESAFIOS. v. V.1, 1999.

MAZZUOLI, V. DE O. Tratados internacionais dos Direitos Humanos. In: Curso de Direito Internacional Público. 5 ed. ed. 2014. p. 813 a 850.

MEIER, BENJAMIN MASON; AYALA, A. S. The Pan American Health Organization and the mainstreaming of human rights in regional health governance. Journal of Law, Medicine \& Ethics, v. Vol.42(3), p. p.356(19), 2014.

MINISTÉRIO DA SAÚDE. PORTARIA $N^{o}$ 426/GM/2005., 2005. Disponível em: <http://bvsms.saude.gov.br/bvs/publicacoes/portaria_426_ac.htm>. Acesso em: 1 jan. 2017.

MORAIS, L. S. DE; FERNANDES, M. S. Aspectos médicos, bioéticos e jurídicos do uso de material genético na reprodução humana assistida "post mortem" a partir de um estudo casuístico. Revista da Ajuris, v. 41, n. 135, 2014.

OEA. Convenção Americana sobre Direitos Humanos, 1969. Disponível em: <http://www.cidh.oas.org/basicos/portugues/c.convencao_americana.htm>. Acesso em: 1 jan. 2017.

ONU -UNESCO. A Declaração Universal sobre o Genoma Humano e os Direitos Humanos. Suíça, 1997.

SALA CONSTITUCIONAL DA CORTE SUPREMA DE JUSTIÇA. COSTA RICA. Sentença $n^{o}$ 2000-02306, de 15 de março de 2000. Processo n ${ }^{\circ}$. 95-001734-007-CO., 2000.

SHELTON, D. Regional protection of human rights. Inglaterra: Oxford. 2008.

SUPREMO TRIBUNAL FEDERAL. Ação Direta de inconstitucionalidade - ADI 3.510/2008, Brasil. 2008.

TRIBUNAL DE JUSTIÇA DA UNIÃO EUROPEIA. Caso Oliver Brüstle v.s Greenpeace, 2011. Disponível em: <http://ec.europa.eu/dgs/legal_service/arrets/10c034_en.pdf>. Acesso em: 15 jan. 2017. 